\title{
The Year of Living Invitationally: Reflections of a First Year Principal
}

\author{
Brendan Byrne Browne \\ St. Vincent Elementary, Ontario, Canada
}

\begin{abstract}
This paper's autoethnographic approach to the study of school leadership is intended to explore the tensions between theory and practice as I straddle this divide as a practicing school principal and academic. While the congruence between theoretical concepts and professional application may not always appear obvious, reflections on my application of the theory of invitational leadership in my first year at the helm of a 400 student elementary school highlights the importance of this connection as theory influences practice and practice, in turn, influences theory.
\end{abstract}

\section{Introduction}

When I pulled up in front of the school for the first time and eased into the reserved Principal's parking spot a few meters away from the front entrance of the building, I decided immediately that the reserved sign would have to go. I sat gazing at the school which was now, for better or worse, subject to my leadership. I had visited with the outgoing Principal in the spring and was introduced to the staff, but it was sitting in the driver's seat of a car filled with cardboard boxes that the gravity of my new role finally settled in. I had decided that I was not going to step into the role and simply see what happened. I would instead be intentional in my approach of creating an inviting school.

I was 33 years old when I pulled into the parking lot and began my tenure as principal. In 2005 the Ontario Principal's Council Leadership Study reported that the average age of elementary school principals in Ontario was 47.3 years of age [20]. I understood that I would not only have to deal with the immense responsibilities inherent in the role, but also with the reality that I was at least 10 years younger than any colleague and 14 younger than the provincial average.

This age gap affected my preparation for the position in the knowledge that public perception would likely raise a collective eyebrow at my age in relation to the role. As a vice-principal I often received the comment "You don't look like a viceprincipal..." and recognized that an archetype of a school principal perhaps does exist. I wondered what a principal was supposed to look like if it was not me.

Not only was my actual age significantly younger than colleagues but I am often told that I look even younger. This affected my self-perception as I began my tenure and influenced my decision to approach the year intentionally from an inviting leadership stance. I could not help but think that my age and deficit in teaching experience in comparison to colleagues would negatively impact my ability to lead the school. I recognized my ability to lead and the faith the board had shown by promoting me and understood that I possessed leadership qualities that was contingent on my communication, relationships, faith, optimism, respect, and genuine care for staff and students. However, despite this recognition, I feared that "charm" played a role in my promotion to a certain degree and that because of my obvious age, I would be "found out" as a leader wanting. The turning point for my approach to leadership came as I read Inviting School Success by Purkey \& Novak, Inviting Educational Leadership by Novak, and Creating Inviting Schools by Novak, Rocco, \& DiBiase which explained the theory of invitational leadership. I recognized the congruence between inviting leadership and my own approach in many ways except one. I was missing the aspect of intentionality. I decided that I needed something solid to hold on to which would inform my decisions and practice. I wanted to have a clear direction which would be obvious to all and an approach to leadership which I could defend. I understood the tensions that would inevitably occur in the role and reveled in the opportunity to be intentional, considerate, and reflective of my practice in an ongoing way. I embraced the invitational theory of practice for these reasons and began my tenure prepared to make decisions, reflect and refine.

\section{Literature review}

Though the transition into formal leadership presents significant challenges for many new principals, the consideration of theory and intentional application can provide support for emerging school leaders.

\subsection{Socialization and shock}


The transition to the role of principal is fraught with stress, isolation, role anxiety, and culture shock as a principal embraces not only instructional leadership, but concurrently managerial, administrative, financial, and supervisory responsibilities [11][12]. Principals are expected to enter the profession adequately prepared to perform all roles and duties competently in order to support student learning and positively influence school culture and administration. The reality is that many principals are overwhelmed by the position as they struggle with their new role identity [2]. Many principals confess to feeling unprepared for the level of expertise required for mediation, difficult parents, teacher supervision, site and facilities management, administrative tasks, and the time and toll taken on families in the role [21]. As I sat in the parking spot reserved for me, I contemplated if I was ready to take on the responsibility.

I had participated in the preparation programs meant to equip me with the theory and skills required for the position. The general consensus from practicing principals is that these programs, while regarded as necessary, fail to adequately prepare emerging principals for the realities of the role [7]. Practitioners and scholars advocate for on-going mentorship to support transitioning principals with their socialization and competency [3][4][6].

The gravity of being in charge settled in my stomach that August day as I prepared to put theory into practice. I was committed to invitational leadership and intended to begin immediately.

\subsection{Theory of practice}

The application of theory may not be at the forefront of many new principal's minds as they begin their tenure as academic leaders. In fact, a perception exists of a gap between theory and practice within education [9]. While education scholars engage in research in order to influence practice through the application of theory, there is little tangible evidence to indicate that these endeavors actually result in change for teachers in the classroom [9]. Though theories about why this gap exists and how to lessen it to bring the world of academia and practitioners closer together, the perceived chasm persists [9]. The language of research is cited as providing a barrier to the dissemination of research to practitioners while a shift in presentation of theory from academic language to that of conversation is suggested as a example of lessening the distance between scholars and teachers [5]. Though this assertion appears deeming to practitioners, further studies reveal that academics and practitioners read very different professional journals.

The reading preferences of scholars and practitioners vary significantly as scholars prefer peer-reviewed journals and practitioners prefer nonpeer reviewed magazines focused on practice and regulations [22]. Despite this perception of a gap between theory and practice, I found myself reimmersed in theory as an academic and a practitioner, reflecting on practice and valuing experience as education.

\subsection{Pragmatism in practice}

Inviting leadership is Dewey-ian in its approach. Dealing with experiences is meant to make experiences better. Concepts must be applicable to action as reality itself is only a result of actually doing something. For life to exist there must be more transaction, reflection, and the development of deeper understanding. Dewey refers to this interaction between the organism and the environment as 'transactional realism' [8]. Without transaction, philosophy is reduced to merely theoretical. It is the process of inquiry that should shape our concept of being [8].

The domain of knowledge and action are not separate, according to pragmatism, but are intimately connected as knowledge emerges from action. In this regard, Dewey would argue that experience is the key to knowledge as experience is the philosophy of action [8].

For pragmatism, educational inquiry is both the beginning and end: it provides the source of the problems while also providing the final "test of value" [1]. Ultimately, the purpose of educational inquiry is to make the actions of the educator more intelligent. Educational research should not be "on" or "for" educators, but needs to actively include educators in a meaningful way in order to be valid and achieve desired goals.

As an educational practitioner, by doing, I am strengthening my theoretical epistemology while theory informs my practice. Theory and practice should not be perceived as dichotomous but rather practice and action are the key to pragmatism. Ultimately, knowledge and truth are not created but possibilities are which open more possibilities. Our understanding of research does not tell us what to do but instead provides options for the future. Pragmatism regards knowledge as a function of human action therefore research and practice must inform each other in a continuous way.

Experience taught me to reflect on practice and reflection lead me back to theories of education. Influenced by the theory of invitational leadership, I began to consider theories 'of' practice rather than theory 'for' practice. I became convinced that invitational leadership would make a positive impact on the school and was determined to put the theory into practice. 


\section{Method and results}

Based on the concept of 'inviting' others to participate in the leadership of the school, invitational leaders foster a culture of open collegial collaboration accomplished through trust, optimism, respect, and intentionality. I dedicated myself to finding out more about the tenants of the theory of inviting educational leadership.

\subsection{Invitational leadership}

Invitational leadership is a theory of practice which resonated with my perception of my own leadership qualities and perhaps more importantly, my belief in the immense talents and potential contributions of others. According to invitational leadership theory, effective leadership is one that invites others to utilize their talents to contribute to the betterment of the organization.

Theory is a way of thinking and practice is that which is worth doing. A theory of practice is thinking about the value of action, being intentional and reflective before, during, and after. Inviting leaders recognize the gifts and talents that others bring to the table and trusts in their ability to contribute to the school. Invitational leaders invite others and work collaboratively with their heart, heads, and hands [13].

As an emerging educational leader, I had respected and encouraged the talents of others and appreciated the collaborative nature of our vocation but recognized my leadership was missing intentionality. Invitational leadership should be intentional where leaders are cognizant of their actions and the repercussions on the staff [3]. I had been given opportunities to lead and would consider myself to be an optimistic, caring, and trusting person by nature, but it was not until I became intentional about my decisions and my practice that I could embrace invitational leadership. I became cognizant of decisions and considerate of the implications of policies, procedures, and programs while reflecting more on practice. Being intentional about my practice required on-going reflection and refinement as Donald Schon details in "The Reflective Practitioner".

Leadership is an art and we have the responsibility for moral action that influences the lives of people [18]. In order to lead invitationally, a leader must respect others, foster trust between people, care for the process of leading, be optimistic that better futures are possible, and be intentional in the process of leading. The way in which this is manifest in school leadership is revealed in the five "Ps": places, policies, people, programmes, and processes.

The invitational leader need not only be aware of interpersonal skills which many other leadership theories focus on but also the way in which the physical environment is inviting as symbols, signs, and the physical make up of a building or room can create an inviting school. Relationships are the key through the development of genuine, mutual respect, being optimistic about situations, people, the future, decisions, and being intentional about it all. Trust is the area that requires the most risk, but an invitational leader trusts that people will make decisions that are congruent with the values and ideals of the school.

While the tenants of trust, respect, optimism, care and intentionality as revealed in places, policies, people, programmes, and processes may seem wonderful in theory and on the page, what does it look like in practice? Presented with the unique opportunity of beginning my tenure as principal, I made the decision to attempt to implement to the theories of invitational leadership in my school.

\subsection{Places}

I began with the physical building by asking the custodian to remove the reserved parking sign. When teachers began to arrive the missing sign was noticed immediately. I told staff why I had removed the sign and invited them to join me by parking in the back. I did not mandate it, suggesting that if there was a reason for them to continue parking in the front then to continue to do so, but by leading by example, staff willingly volunteered parking spots in front of the school to provide more for visitors.

As a vice-principal, I had spent one year between two schools and a year at another school. In those three offices I occupied, I inherited the space from my predecessor and left it unchanged. In each configuration, there was a desk in the middle of the room which I sat behind. I was cognizant of the power structure that it created in the room and the dynamic that each visitor would experience upon entering the office as I sat behind the desk and invited them to sit on the other side. Though the physical set up of the office was not congruent with my leadership style, my lack of confidence and my own perception of competence influenced me to leave it in all three schools the same way. As I prepared for my new role as principal, I began to recognize that I had left each office intentionally uninviting because of my insecurity in regards to the perception of my competency as a result of my age. Though I did not enjoy the power dynamic that each office offered, I perceived that it afforded me a degree of authority. As I transitioned into the principal role, I was determined to embrace an inviting approach entirely which included the careful consideration of the physical space.

I went about the process of creating an inviting office. My predecessor sat behind a large desk as visitors entered the office to sit in two chairs on the other side of the desk. The walls were lined with 
large black filing cabinets and bookshelves which forced visitors to turn sideways to enter the room and sit down. I removed two of the filing cabinets and one of the two desks and pushed the desk up against the wall. An inviting office would not present a desk as a barrier to interaction and a symbol of power. I wanted to be able to work at my desk and simply turn to face any visitors with my body open and inviting to conversation and relationships. The removal of the filing cabinets created space for a small circular table and two chairs which I pushed into the corner for conversations and intimate conferences.

I filled the room with books to lend to staff, students, or parents from classic literature to philosophy, comic books to biographies of Roy Keane, Louis Riel, and George Best. Paintings which were gifts from parents at former schools and art work from my young daughter were hung on the wall along with my degrees, and photos of my family to reveal my priorities. Lastly, I cleared large cork board wall of all paper with phone numbers, schedules, and administrative information to create a blank canvass on which I would place student work.

I walked the hallways and took note of the signs within the school. Signs that professed our school to be an allergen-free environment by saying "stop!" on a red stop sign were re-created to thank everyone for contributing to the creation of a safe learning environment for all students. The stop sign at the front door of the school which indicated that the school doors are locked throughout the day for security reasons was turned into a welcome note that invited visitors to press the button to reach our secretary and be welcomed in the school at the office.

Alone before the school year began, I took advantage of the opportunity to create an inviting environment before everyone arrived back. The changes, though small, were noticed, and sent the message that my leadership intended to be inviting, open, and collaborative.

\subsection{Policies}

I discovered that the simple act of leaving my door open to be a strong indicator of invitational leadership. With the layout of my office open for visitors, my door remains open and inviting. The staff and parents appreciated access for questions and concerns, and my priorities became obvious.

At the first staff meeting of the year, I asked for teachers to send students to the office for doing 'good things'. Random acts of kindness or displays of thoughtful, caring behavior were to be applauded and recognized by me in the office. I asked for students who were steadily improving, scored highly on a test, or had completed a project they were particularly proud of. This policy took both the staff and students a while to get used to as the principal's office had long been considered a destination for students requiring discipline or poor effort. I was delighted as students came to my office with poems they had written to read to me, a test to share, or a story about how they were caught doing something special for others in the school. Students were delighted to be recognized and the principal's office started to become demystified from traditional perceptions of discipline and fear - perceptions which I have found to be ever-present still, despite an invitational approach. This perception turned from a scary place to go to a place where scholarship and citizenship are celebrated. I began to place students' work onto my large corkboard as they came down to the office to share. The board was filled quickly with evidence of student success and pride.

School policies continue to reflect the consideration of the best interests of the students. When that priority and policy is clear to all community members, decisions, even potentially unpopular ones, are accepted and respected quickly.

\subsection{People}

When I walked into the school for the first time that August morning, I was feeling overwhelmed and underprepared to take on the leadership of the school and didn't pretend otherwise. I sat down with the school's secretary who over twenty five years had seen many principals come and go. I listened to her opinions, ideas, and observations. I did the same with the custodian. At the August staff meeting, I asked each staff member to make an appointment with me before the October long weekend for a one on one conversation for an hour or so to talk about them: their career, future plans, impressions and opinions of the school, family life, talents, and expertise. I found out so many interesting and wonderful things about each unique staff member both personally and professionally which helped me to understand more about each individual and the school as a whole. By the time I had met with the last member of staff that fall, I had spent over fifty hours in meetings and considered it the most wonderful and effective use of my time.

I met with the school Council Chair to get his input and feedback on the school and community, and began to develop a partnership with the community. I asked questions, listened, and found out more about our unique school and greater community than I had ever imagined.

As an invitational leader, I made it my priority to remember everyone's name and learn a little about them. As the year progressed, I was intentional about meeting every student and parent I could, and prided myself on knowing every student in the school; their siblings, parents, and some background, 
by the end of the year. The building itself is not what makes the school but rather it is the people within. Investing in the relationships within the building through the simple act of knowing each individual is an extremely powerful statement.

Daily routines reveal people-centric practices. The practice I feel has made the largest impact on the community is my morning and evening routines at the bus drop off and the 'kiss and ride' at the side of the school. Every morning, I greet the buses as they arrive and drop off students each day. A personal 'good morning' to each student as they exit the bus and walk toward the yard is usually one of the highlights of my day. From the buses, I walk to the side of the school for the kiss and ride car drop off. I open each car door, and wish everyone a good morning. Usually this means the traffic moves quickly and efficiently, students arrive safely, and they are greeted with a warm welcome.

Staff appreciated the active engagement in student safety and supervision. Parents quickly grew to love this morning ritual as it made drop off quicker and safer while allowing me to stay in touch with parents each day to say hello, or to quickly follow up on any situations or conversations. I remain convinced that this practice continues to lessen the number of phone calls and meetings throughout the day while setting a positive example of an inviting and welcoming school.

At the end of the day, being outside for bus duty to similarly welcome parents for pick up, assist students to their buses efficiently and safely, and direct traffic for ease and safety for both buses and cars reveals my accessibility, priorities, and open leadership.

Daily routines include classroom visits and yard duty for supervision. Not only does this allow for more visibility around the school, but it affords a greater understanding of the school, staff, and students. It is easy to profess priorities, but I continue to find that practices reveal priorities. Time is so precious to a school principal and when the regular practice is so open, inviting, and engaged, the priorities of the inviting leader are even more obvious.

\subsection{Processes}

I invited staff to submit their ideas for what they thought worked well in the school, what they would like to begin, and anything they would like to start. This simple process of seeking their input valued their immense knowledge of the school and signaled a more collaborative approach to processes within the school.

I found out that the staff and students were not happy with the school crest as it had existed for many years and were interested in moving in a new direction. I invited the entire school community to submit their ideas for a new school crest.
I was unsure about what to expect but the ideas started to roll in on 8"11" paper with suggestions for a variety of mascots, crests, and logos for consideration. Submissions arrived from the Kindergarten students up to the Grade 8 s. By the time the submissions were all in, more than $80 \%$ of the school's population participated in the process.

We took every submission, mounted it, and displayed them around the school as a school crest art show. Students enjoyed seeing their work mounted while everyone carefully considered and discussed the unique entries.

In the end, the many crests were narrowed down to three which were then taken and combined to make up what is now our new school crest. Those original three submissions, along with an explanation of the project, how they were chosen, what they represent, and the new crest that resulted now hangs in the front hallway as a remembrance of their work and of our collective contributions to change and community. Our school crest project engaged the entire community in the contribution and decision making process which resulted in the new public symbol of our school. Not only was it a wonderful exercise in collective creativity, but it also highlighted our commitment to inviting ideas and collaborative contributions to the community.

\subsection{Programs}

I intended to make social justice a priority within the school so that our students could recognize the responsibility they have to serve others and how it can be done in any measure, large or small. The Council Chair and I began by introducing the students to Bethany Kids Pediatric Hospital in Kijabe, Kenya which provides free surgeries and medical care to children from across East Africa. At Bethany, children with disabilities from across Africa and specifically Kenya and Somalia are given medical attention and important surgeries to address medical issues such as spina bifida, hydrocephalus, and cleft palate. Children are also operated on as a result of burns, trauma from conflicts, and other physical and developmental disabilities.

The project was simple: students were encouraged to give only their own money which they had earned themselves through chores, allowances, or any other creative way in which they could earn money for themselves. They were given a specific timeline for the project, but no financial goals were stated. We wanted students to give generously without the glare of recognition and the influence of what others were giving. There were no promises of pizza parties or prizes for the largest contributions. All donations were secret as only the donors would know their contribution. We similarly encouraged parents to match their children's contribution penny for penny in the spirit of community. 
Students began to talk about how they were giving away portions of their allowance while others suggested extra chores around the house. By the second week the buzz around the school was infectious. Grade 4 students hosted a cupcake sale on their front lawn to earn money to give away while Grade 5s took advantage of the cold early March temperatures to host a hot chocolate sale. Other Grade 5 students purchased pizza and set up a stand in front of the local high school selling to their teenage customers. A class organized a crazy hair day for a dollar a student. Teachers actively encouraged and lead by example while parents contributed by hosting jewelry sales and individual contributions. Parents became excited about what the staff was doing and teachers applauded the efforts of the parents and together they recognized the commitment of the students to service and philanthropy.

When this project was initiated we had hoped to bring the community together, united in a common ethical goal. We had hoped that students would recognize that they could think globally and act locally and understand that their efforts, no matter how large or small, can make an impact. We intended to inspire students to place the needs of others before their own and plant the seeds of philanthropy. Sometimes when we take on projects like this we only recognize the impact through a retrospective lens however, we would not have to wait that long.

I received a phone call during the last week of the project from a parent informing me that her son's birthday was on the weekend and that he had invited all of the students in both Grade 6 classes to his party. In lieu of traditional birthday gifts, he had asked instead for contributions for Bethany. When Monday morning rolled around, he walked into my office and personally handed me over $\$ 500$. He understood that he didn't need anything. Not in comparison to the children at Bethany. Similarly, a Grade 2 student hosted a birthday party with a similar request from her attendees. I was moved beyond words.

Everyone in the school rallied together in pursuit of a common moral purpose and in the process contributed to the community and positive school culture.

\section{Conclusion}

The transition into a position of such immense responsibility as a school principal is a difficult one. A new leader moves from being overwhelmed to coping to a level of competency eventually acquiring expertise and self efficacy. Many scholars write about these stages as rites of passage for emerging leaders [15][16].
As a new school principal I felt overwhelmed and underprepared for the responsibilities inherent within the role. I had studied within preparation programs and academia and appreciated the theoretical foundations of Pragmatism and wondered how that would look in practice. Invitational leadership provided a theory of practice rather than a theory for practice, respecting the contributions of experience and reality rather than suggesting prescriptive approaches to leadership which connected with my philosophical inclinations and leadership aspirations. For Dewey, experience is the process of undergoing something, and being reflective and considerate of how to improve for future practice. There is a selfcorrecting component of this approach to practice as I embraced Michael Fullan's "ready, fire, aim" [10] philosophy. I committed to living in an idea and invited others to live intentionally within the school by doing things on purpose for purposes that we could defend. I considered myself to be a trusting, caring, respectful, and generally optimistic leader but had been so unintentionally. Invitational leadership invited me to be intentional about my practice and reflective on my action. This shift in focus toward intentional practice grounded my practice and serves as an example of theoretical influence on educational leadership.

These reflections are not intended to suggest "successful" leadership. They simply reveal the real impact and applicability of the theory of invitational leadership in contemporary schools as evidence of the intentional bridging of the knowledge gap and the evaluation of considerate educational leadership grounded concurrently in theory and practice.

The implementation of invitational leadership continues to make a profound impact on my practice as a school principal. By intentionally caring, respecting, trusting, and being optimistic, my experiences continue to shape my decision making and ultimately, my leadership as theory influences practice and practice influences theory.

\section{References}

[1] Biesta, G. J. J. and Burbles, N. C. (2003) Pragmatism and educational research. Toronto: Rowan \& Littlefield Publishers, Inc.

[2] Browne-Ferrigno, T. \& Muth, R. (2006). Leadership mentoring and situated learning: Catalysts for principalship readiness and lifelong mentoring. Mentoring and Tutoring. 14(3), pp. 275-295.

[3] Browne-Ferrigno, T. \& Muth, R. (2004). Leadership mentoring in clinical practice: Role socialization, professional development, and capacity building. Educational Administration Quarterly. 40(4), pp. 468-494.

[4] Browne-Ferrigno, T. (2003). Becoming a principal: Role conception, initial socialization, role-identity 
transformation, purposeful engagement. Educational Administration Quarterly. 39(4), pp. 468-503.

[5] Carson, T.R. (1986). Closing the gap between research and practice: Conversation as a mode of doing research.Phenomenology and Pedagogy, 4(2), 73-85.

[6] Chapman, J. D. (2005). Recruitment, retention, and development of school principals. International Academy of Education. UNESCO: Paris.

[7] Daresh, J. \& Male, T. (2000). Crossing the border into leadership: Experiences of newly appointed british headteachers and American principals. Educational Management \& Administration. 28(1), pp. 89-101.

[8] Dewey, John. (1938). Experience and education. New York: Simon and Shuster.

[9] Davis, S. H. (2007). Bridging the gap between research and practice: What's good, what's bad, and how can one be sure? Phi Delta Kappan. 88(8), 568-578.

[10] Fullan, M. (2001). Leading in a culture of change. San Francisco: Jossey-Bass.

[11] Holland, P.E. (2004). Principals as supervisors: A balancing act. NASSP Bulletin. 88(639), pp.3-14.

[12] Loder, T.L. \& Spillane, J.P. (2005). Is a principal still a teacher?: US women administrator's accounts of role conflict and role discontinuity. School Leadership and Management. 25(3), pp. 263-279.

[13] Novak, J. M. (2002). Inviting educational leadership. Toronto: Pearson Education.

[14] Novak, J.M., Rocca, W., \& DiBiase, A.M. (2006) Creating inviting schools. San Francisco: Caddo Gap Press.
[15] Oplatka, I. (2004). The prinicpal's career stage: An absent element in leadership perspectives. International Journal of Leadership in Education. 7(1), pp. 43-55.

[16] Parkay, F.W., Currie, J.D., \& Rhodes, J.W. (1992). Professional socialization: A longitudinal study of first time high school principals. Educational Administration Quarterly. 28(1), pp. 43-75.

[17] Purkey, W.W. \& Novak, J. (1996). Inviting school success: A self-concept approach to teaching, learning,and democratic practice, $3^{\text {rd }}$ edition. Florence, Kentucky: Wadsworth Publishing Inc.

[18] Purkey, W. W. \& Siegel, B.L. (2003) Becoming an invitational leader: A new approach to professional and personal success. Humanics Trade Group.

[19] Schon, D. (1983). The reflective practitioner: How professionals think in action. New York: Basic Books.

[20] Stone, H., Parker, J.D.A., \& Wood, L.M. (2005), Report on the ontario principal's council leadership study. Retrieved April 25, 2009 from The Ontario Principal's Council.

Website:http://www.principals.on.ca/cms/display.aspx?pid $=4509 \& \mathrm{cid}=5446$

[21] Walker, K., Anderson, K, Sackney, J. \& Wolfe, J. (2003). Unexpected learning by neophyte principals: factors related to success of first year principals in schools. Managing Global Transitions. 1(2), pp. 195-213.

[22] Zirkel, P.A. (2007). The professoriate, the practitioners, and 'their' periodicals. Phi Delta Kappan. 88(8), 586-589. 